\title{
Primary tubal choriocarcinoma
}

\section{Neetha Nandan*, Kishan Prasad, Mubeena Beegum, Supriya Rai}

Department of Obstetrics and Gynecology, K. S. Hegde Medical Academy, Deralakatte, Mangaluru, Karnataka, India

Received: 02 April 2018

Accepted: 05 May 2018

\section{*Correspondence:}

Dr. Neetha Nandan,

E-mail: nvyas_21@yahoo.com

Copyright: (c) the author(s), publisher and licensee Medip Academy. This is an open-access article distributed under the terms of the Creative Commons Attribution Non-Commercial License, which permits unrestricted non-commercial use, distribution, and reproduction in any medium, provided the original work is properly cited.

\begin{abstract}
Choriocarcinoma is extremely aggressive form of gestational trophoblastic disease. It occurs due to neoplastic changes in the chorionic villi. The most common site of origin is uterus but rarely can occur in tube, cervix or ovary. Tubal choriocarcinoma may develop either by malignant transformation of a tubal pregnancy or can arise denovo without an ectopic pregnancy. The reported incidence of tubal choriocarcinoma is approximately 1.5/1,000,000 births. Here, we report a case in which salphingectomy was done thinking it was an acute ectopic pregnancy, but histopathological examination showed tubal choriocarcinoma. This tubal choriocarcinoma occurred denovo and was not secondary to an ectopic pregnancy. Patient did not need adjuvant chemotherapy as it was detected early and is being followed up by $\beta$-hcg monitoring.
\end{abstract}

Keywords: Choriocarcinoma, Ectopic pregnancy, Fallopian tube, Gestational trophoblastic disease

\section{INTRODUCTION}

Gestational choriocarcinoma is a malignant type of Gestational Trophoblastic Disease (GTD) which usually originates in uterine cavity. But this can rarely affect fallopian tubes, ovaries, cervix, vagina and omentum. Choriocarcinoma usually develops after a molar pregnancy and can occur to a lesser extent after a term pregnancy, abortion or ectopic pregnancy. The reported incidence of tubal choriocarcinoma is approximately $1.5 / 1,000,000$ births which constitute $0.8 \%$ of all GTD. ${ }^{1}$

The choriocarcinoma associated with ectopic pregnancy is extremely rare with incidence of $0.76-0.4 \%$ of all ectopic pregnancies but it is generally very aggressive. ${ }^{2}$ The incidence reported in a study is one in 5333 tubal pregnancies and one in 1.6 million normal intrauterine pregnancies. ${ }^{3}$ Choriocarcinoma is a biphasic malignant proliferation of cytotrophoblast and syntiotrophoblast without chorionoic villi. Tubal choriocarcinoma has a very aggressive behavior because of relatively thinner muscular layer of the fallopian tubes and early rupture of tubal wall. Therefore, tubal choriocarcinoma is mostly metastatic when diagnosed.

\section{CASE REPORT}

A 29 year old lady presented to author's out patient department with 42 days of amenorrhoea, pain abdomen and spotting per vagina. Urine pregnancy test was positive. Vitals were stable. Abdominal and vaginal examination was unremarkable. She had a normal delivery 6years back. There was no history of previous abortions, ectopic pregnancy or use of any contraceptives earlier. Transvaginal sonography showed empty uterine cavity with left adnexal mass of $2 \times 2 \mathrm{~cm}$ suggestive of ectopic pregnancy. Beta human chorionic gonadotropin ( $\beta$-hcg) level was $1270 \mathrm{mUI} / \mathrm{ml}$. As patient had severe pain, author ahead with laparoscopy. Intraoperatively, there was a $2 \times 2 \mathrm{~cm}$ left tubal mass at isthmo-ampullary junction. There was a breach noted at the mesosalphinx (base of the tubal mass) with an organized clot of 200gms but there was no active bleeding from that site. Left salphingectomy was done. 
Histo-Pathological Examination (HPE) showed proliferation of syntiotrophoblast and cytotrophoblast cells with nuclear atypia with areas of hemorraghe in the fallopian tube (Figure 1 and 2).

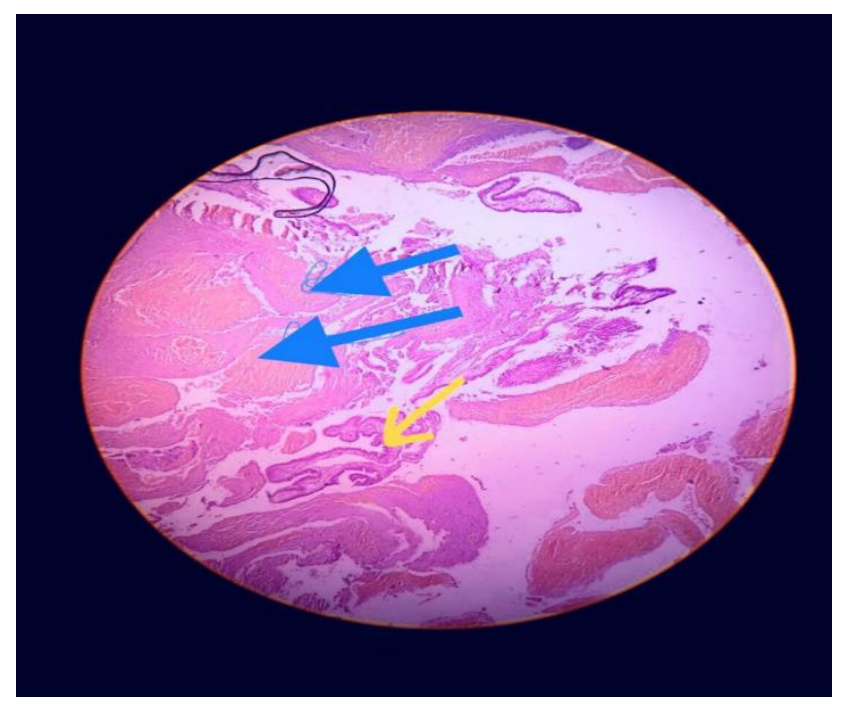

Figure 1: Normal fallopian tube (yellow arrow) with areas of haemorrhage (blue arrows).

Postoperative period was uneventful. Follow up $\beta$-hcg (weekly) reduced to $38,4,0.5,0.2 \mathrm{mUI} / \mathrm{ml}$ respectively. Follow up chest $\mathrm{x}$-ray and Ultrasound abdomen-pelvis was normal. To rule out metastatic disease, CT chest was done and was normal. Ideally MRI brain and pelvis should have been considered to complete work up for metastatic disease. Since the $\beta$-hcg level was low and had a rapid fall after the surgery, it was assumed that there was no metastatic disease. Presently, patient has been adviced contraception and is being followed up for 12 months with monthly $\beta$-hcg levels which have been normal.

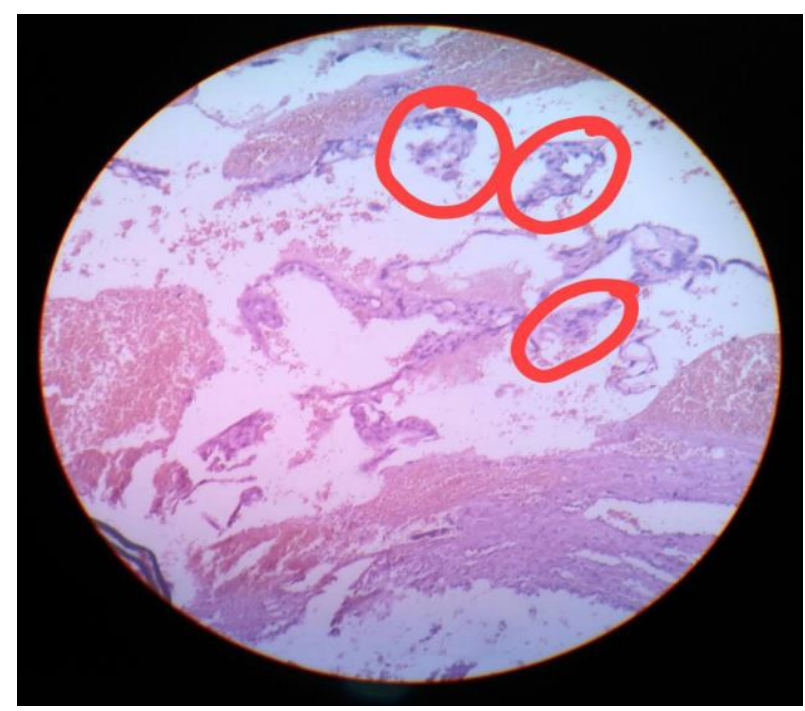

Figure 2: Tumor cells with nuclear atypia.

\section{DISCUSSION}

Though the incidence of tubal choriocarcinoma is rare, it has a very aggressive course. Tubal choriocarcinoma is mostly metastatic when diagnosed. Choriocarcinoma has greater tendency to invade the vessels and hence can metastasize lungs, brain and liver. ${ }^{4}$ Reportedly, $75 \%$ cases have metastasis during initial diagnosis unlike our case where it has been detected early. Because of it's highly metastatic potential, chemotherapy becomes essential as a part of the treatment. The diagnosis of tubal choriocarcinoma is challenging as the clinical symptoms are non-specific and can mimic hemorraghic ovarian cyst, tubo-ovarian mass, ovarian tumor and ectopic pregnancy. ${ }^{5}$ The delay in diagnosis increases the morbidity. In this case, it seems like choriocarcinoma has occurred de novo in the tube without a prior tubal pregnancy. That's the reason for $\beta$-hcg being so low here unlike previously reported cases where the levels are very high as choriocarcinoma occurred secondary to tubal pregnancy. This is the also the reason why patient did not need treatment with chemotherapy as the tumor was completely excised at the earliest. To the best author's knowledge, this a one of the rare case of a denovo primary tubal choriocarcinoma managed by surgical excision and which did not require chemotherapy. Tubal choriocarcinoma may develop either by malignant transformation of a tubal pregnancy or can arise denovo without an ectopic pregnancy. The clinical findings usually mimic an ectopic pregnancy that is amenorrhoea, increased levels of $\beta$-hcg, vaginal bleeding and pelvic pain. There are no specific imaging findings to diagnose extrauterine choriocarcinoma.

Diagnostic errors occur due to it's rarity, it's presentation mimics tubal pregnancy and lack of discriminating immunohistochemistry. ${ }^{6}$ Histopathological examination is gold standard for diagnosing choriocarcinoma. The typical histology shows columns of synctiotrophoblast and cytotrophoblast cells with nuclear atypia without any evidence of villous structure invading vessels and muscular tissue with extensive necrosis and hemorraghe. Hence, HPE verification of all ectopic pregnancy has to be made mandatory to exclude other tubal pathology. ${ }^{7}$ Before the advent of modern chemotherapy, gestational choriocarcinoma carried a mortality rate of $90 \%$. Most patients died due to distant metastasis. Tubal choriocarcinoma is highly chemosensitive and has good prognosis if detected early. ${ }^{8}$ Management includes complete surgical resection combined with subsequent adjuvant chemotherapy and $\beta$-hcg monitoring. ${ }^{9} \beta$-hcg is a sensitive tumor marker for choriocarcinoma. Women treated for tubal choriocarcinoma should be closely monitored with $\beta$-hcg for atleast 2 years after completion of treatment and should receive contraception during this period. There are reports demonstrating the usefulness of combination of P57KIP2 immunostaining and DNA polymorphism analysis determining the origin of tubal choriocarcinoma (gestational and non-gestational). ${ }^{10}$ 


\section{CONCLUSION}

This case highlights the importance of performing histopathological examination of tubal specimens in all patients who present as tubal pregnancy. By doing so, we may not miss on such extremely rare highly aggressive malignancy which can be curable.

Funding: No funding sources

Conflict of interest: None declared

Ethical approval: Not required

\section{REFERENCES}

1. Mehrotra S, Singh U, Goel M, Chauhan S. Ectopic tubal choriocarcinoma: a rarity. BMJ case reports. 2012;bcr-2012-006318.

2. Nayama M, Lucot JP, Boukerrou M, Collinet P, Cosson M, Vinatier D. Tubal choriocarcinoma: a case reporteview of the literature. J Gynecol Obstet Biol Reprod. 2007;36(1):83-6.

3. Chen MJ, Yang JH, Lin MC, Ho HN, Yang YS. An unusual gestational choriocarcinoma occurring primarily on the surface of a subserous leiomyoma. BJOG: Int J Obst Gynaecol. 2004;111(2):188-90.

4. Karaman E, Çetin O, Kolusari A, Bayram I. Primary tubal choriocarcinoma presented as ruptured ectopic pregnancy. J Clin Diag Res. 2015;(9):QD17.
5. Meddeb S, Rhim MS, Zarrouk W, Bibi M, Yacoubi MT, Khairi H. Unusual gestational choriocarcinoma arising in an interstitial pregnancy. Int J Surgery case Reports. 2014;5(11):787-8.

6. Tasha I, Kroi E, Karameta A, Shahinaj R, Manoku N. Prevalence of gestational trophoblastic disease in ectopic pregnancy. J Prenat Med. 2010;4(2):26.

7. Beena D, Teerthanath S, Jose V, Shetty J. Molar pregnancy presents as tubal ectopic pregnancy: a rare case report. J Clin Diag Res. 2016;10(1):ED10.

8. Galvez CR, Fernandez VC, De Los Reyes JM, Jaén MM, Teruel RG. Primary tubal choriocarcinoma. International J Gynecol Can. 2004;14(5):1040-4.

9. Hook J, Seckl M. Management of trophoblastic disease. IN: Dunlop W, Ledger EL. eds. Recent advances of obstetrics and gynecology. London: The royal society of medicine press Ltd. 2008;24:147148.

10. Nakayama M, Namba A, Yasuda M, Hara M, Ishihara O, Itakura A. Gestational choriocarcinoma of Fallopian tube diagnosed with a combination of p57KIP2 immunostaining and short tandem repeat analysis: case report. 2011;37(10):1493-6.

Cite this article as: Nandan N, Prasad K, Beegum M, Rai S. Primary tubal choriocarcinoma. Int J Reprod Contracept Obstet Gynecol 2018;7:2509-11. 